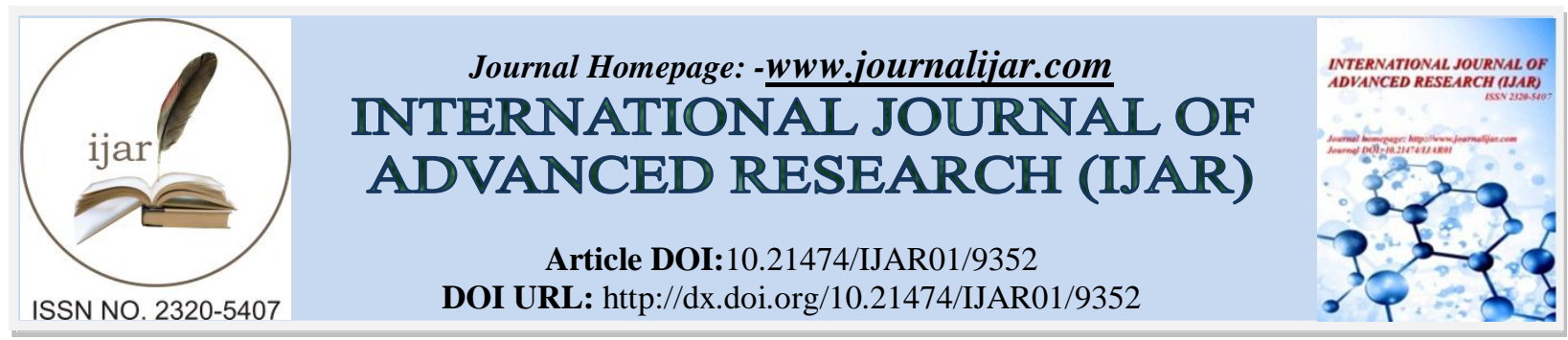

RESEARCH ARTICLE

\title{
IN VITRO EVALUATION OF ANTHELMINTIC ACTIVITY OF ETHANOLIC EXTRACT OF LEAVES OF TOONA CILIATA M. ROEM ON INDIAN EARTHWORM.
}

\author{
Saumya Kanti Sinha ${ }^{1}$, Mayanglambam Medhabati ${ }^{2}$, Surjit Nongthombam ${ }^{1}$, Rikrak Gabil Momin ${ }^{1}$, Athira \\ Muralidas ${ }^{1}$ and Paonam Shyamasakhi ${ }^{2}$. \\ 1. Post Graduate Trainee, Department of Pharmacology, Regional Institute of Medical Sciences, Imphal, Manipur. \\ 2. Associate Professor, Department of Pharmacology, Regional Institute of Medical Sciences, Imphal, Manipur.
}

\section{Manuscript Info}

Manuscript History

Received: 05 May 2019

Final Accepted: 07 June 2019

Published: July 2019

Key words:-

Anthelmintic drugs, albendazole, Toona ciliata M. Roem.

\begin{abstract}
Helminthiasis is one of the most prevalent and preventable infestations worldwide. Globally about 1.45 million people are infested with soil transmitted helminths with the bulk of the burden shared by developing countries like India. Emerging resistance and accompanying side effects to the currently available anthelmintic drugs is a major concern and newer anthelmintics with novel mode of action is the need of the hour. So, this study has been undertaken for evaluating the anthelmintic activity of ethanolic extract of leaves of Toona ciliata M. Roem (EETC) on Indian earthworms (Pheretima posthuma). The earthworms (5-8 $\mathrm{cm}$ in length) were divided into 4 groups with six worms in each group. $2 \%$ gum acacia was used as control (group 1), albendazole 25 $\mathrm{mg} / \mathrm{ml}$ as standard (group 2) and EETC $25 \mathrm{mg} / \mathrm{ml}$ and $50 \mathrm{mg} / \mathrm{ml}$ as test drugs in group 3 and 4 respectively. Time taken for paralysis and death of worms were observed individually and recorded. The plant showed significant anthelmintic activity $(\mathrm{p}<0.001)$ but less potent than the standard drug.
\end{abstract}

Copy Right, IJAR, 2019,. All rights reserved.

\section{Introduction:-}

Helminths have plagued humans from the earliest of centuries as evident from the ancient writings of Hippocrates, Egyptian medical papyri and the Bible. ${ }^{1,2}$ Currently they pose a major threat to public health contributing to the prevalence of malnutrition, anaemia, eosinophilia and pneumonia in the developing countries. ${ }^{3}$ Global estimates of 2010 states 438.9 million people being infested by hook worm (Ancylostoma duodenale), 819 million people by round worm (Ascaris lumbricoides), 464.6 million people by whip worm (Trichuris trichiura). ${ }^{4}$ India contributes to as much as $21 \%$ of the global burden of soil transmitted helminthiasis (STH) out of which more than $50 \%$ belong to the school aged children. ${ }^{5}$

The pathogenesis of helminth infestation involves entry of the parasite either by faeco-oral route or directly through the skin of the host and lodgment in the intestine. ${ }^{6}$ Gastro-intestinal symptoms like abdominal pain, diarrhea; malabsorption, anaemia, perianal pruritis and eosinophilic pnemonitis are the myriad of symptoms produced by helminth infestation which though are rarely fatal but diminishes working capacity. ${ }^{7}$

Corresponding Author:-Paonam Shyamasakhi.

Address:- Associate Professor, Department of Pharmacology, Regional Institute of Medical Sciences, Imphal, Manipur. 
Anthelmintic drugs either kill or expel the infesting worms. They include benzimidazole class like albendazole \& mebendazole, macrocyclic lactone like ivermectin or pyrazinoisoquinoline derivative like praziquantel. Mebendazole and albendazole inhibits polymerization of $\beta$ tubulin of the parasite. In addition, they probably block glucose uptake in the parasite and deplete its glycogen stores. ${ }^{8,9}$ The emergence of resistance to all currently used anthelmintic drugs is a major concern and newer anthelmintics with novel mode of action is the need of the hour. ${ }^{10}$ Indian traditional medicine like Ayurveda, Unani, Siddha have long been using plant derived medicines as the remedy of different ailments. For effective yet non-toxic treatment of helminthiasis, the research on plant derived drug therapy is greatly required. ${ }^{11,12}$ Toona ciliata M. Roem locally known as "Tairel” in Manipuri, "Tun" in Hindi or the "Indian Mahogany" in English, possesses many important biological properties that account for its traditional use in medicinal treatments. The bark is useful in chronic dysentery, leprosy, fever, headache and blood complaints etc. Leaves are used in vomiting, diarrhea, skin diseases, small pox and as insect repellant. Various previous studies have suggested that the leaves of Toona ciliata M. Roem exhibit anti-diabetic, anti-ulcer, anti-inflamatory, antimicrobial and anti-fungal activities. ${ }^{13,14}$ Divakar et $\mathrm{al}^{15}$ studied the phytochemical constituents of Toona ciliata M. Roem and found the presence of coumarin, phenolic and polyphenols, terpenes and terpenoids, steroids, flavonoids, limonoids and nor-limonoids, polyynes and tannin compounds.

As such, considering its use in gastro-intestinal ailments by locals, the present study was undertaken to evaluate in vitro, the anthelmintic effect of ethanolic extract of leaves of Toona ciliata M. Roem on Indian earthworms (Pheretima posthuma).

\section{Material and Methods:- \\ Plant materials}

The present study was conducted in the Department of Pharmacology, Regional Institute of Medical Sciences, Imphal, Manipur. The plant was collected from the foothills of Langol Range, Imphal, Manipur and authenticated by the Department of Botany, D.M. College, Imphal as Toona ciliata M. Roem having Acc. No. DM 201/2010.

\section{Preparation of plant extract}

The leaves of the plant were shade dried and powdered using a mixer grinder and ethanolic extract was obtained by the extraction procedure using soxhlet apparatus as described by Knevel AM et al. ${ }^{16}$ The percentage yield was $18 \%$ and the extract thus obtained was used for the anthelmintic study.

\section{Experimental worms}

The experiment was done on adult Indian earthworm (Pheretima posthuma) owing to its anatomical and physiological resemblance with Ascaris lumbricoides. ${ }^{17,18}$ The earthworms $(5-8 \mathrm{~cm}$ in length) were collected from moist soil and authenticated by the Department of Life Sciences, Manipur University. They were cleaned with normal saline (NS $0.9 \%$ ) to remove any dirt or debris.

\section{Evaluation of anthelmintic activity}

The earthworms were divided into 4 groups with six worms in each group. $2 \%$ gum acacia was used as control (group 1), albendazole $25 \mathrm{mg} / \mathrm{ml}$ as standard (group 2) and EETC $25 \mathrm{mg} / \mathrm{ml}$ and $50 \mathrm{mg} / \mathrm{ml}$ as test drugs in group 3 and 4 respectively. Standard and test drugs were dissolved in $2 \%$ gum acacia and $10 \mathrm{ml}$ of desired formulation was poured in separate petridish and the worms were placed in it one at a time. Time taken for paralysis and death of worms were observed individually. Time for paralysis was noted when no movement of any sort could be observed except when the worms were shaken vigorously. Time for death of individual worm was recorded when worms showed no movement even after vigorous shaking or dipping in the warm water $\left(50{ }^{\circ} \mathrm{C}\right)$ followed by fading of their body colour. ${ }^{19,20,21}$

\section{Statistical analysis}

Data were analysed using One way ANOVA followed by Bonferroni test post hoc. Results were expressed in mean \pm SEM.

\section{Results and discussions:-}

The ethanolic extract of leaves of Toona ciliata M. Roem (EETC) had significant anthelmintic activity when compared with control $(\mathrm{p}<0.001)$. The standard drug albendazole at $25 \mathrm{mg} / \mathrm{ml}$ showed best activity for time of paralysis and death $(11.68 \pm 0.49$ and $16.21 \pm 0.30$ mins. respectively $)$, while EETC $(25 \mathrm{mg} / \mathrm{ml})$ showed $23.06 \pm$ 
0.97 and $30.15 \pm 0.84$ mins. respectively and EETC $(50 \mathrm{mg} / \mathrm{ml})$ showed $16.23 \pm 0.55$ and $21.51 \pm 0.52 \mathrm{mins}$ respectively for time of paralysis and death. Moreover higher dose of EETC $(50 \mathrm{mg} / \mathrm{ml})$ showed significant ( $\mathrm{p}<0.001)$ increased anthelmintic activity as depicted by the reduced time of paralysis and death (Fig 1 and 2 ). However the extract at either dose was found to be less effective than the standard drug.

Table 1:-In vitro anthelmintic activity of EETC on Indian earthworms

\begin{tabular}{|c|c|c|c|}
\hline Group & Drug & Time of paralysis(in min.) & Time of death(in min.) \\
\hline 1 & Control(2\% gum acacia) & $0.00 \pm 0.00^{\mathrm{b} * \mathrm{c}^{2} \mathrm{~d} *}$ & $0.00 \pm 0.00^{\mathrm{b}^{*} \mathrm{c} * \mathrm{~d} *}$ \\
\hline 2 & $\begin{array}{l}\text { Standard(Albendazole } \\
25 \mathrm{mg} / \mathrm{ml})\end{array}$ & $11.68 \pm 0.49^{a^{*} c^{*} d^{*}}$ & $16.21 \pm 0.30^{\mathrm{a}^{*} \mathrm{c}^{*} \mathrm{~d} *}$ \\
\hline 3 & EETC $(25 \mathrm{mg} / \mathrm{ml})$ & $23.06 \pm 0.97^{\mathrm{a} * \mathrm{~b}^{*} \mathrm{~d} *}$ & $30.15 \pm 0.84^{\mathrm{a} * b^{*} d^{*}}$ \\
\hline 4 & EETC $(50 \mathrm{mg} / \mathrm{ml})$ & $16.23 \pm 0.55^{\mathrm{a} * \mathrm{~b} * \mathrm{c}^{*}}$ & $21.51 \pm 0.52^{\mathrm{a}^{*} \mathrm{~b}{ }^{*} \mathrm{c}^{*}}$ \\
\hline
\end{tabular}

Results were expressed in Mean \pm SEM. Symbols a, b, c and d were used to compare with group 1,2,3,4 respectively. ${ }^{*} \mathrm{p}<0.001$.

Fig 1:-Anthelmintic activity of EETC when compared to standard drug albendazole on time of paralysis.

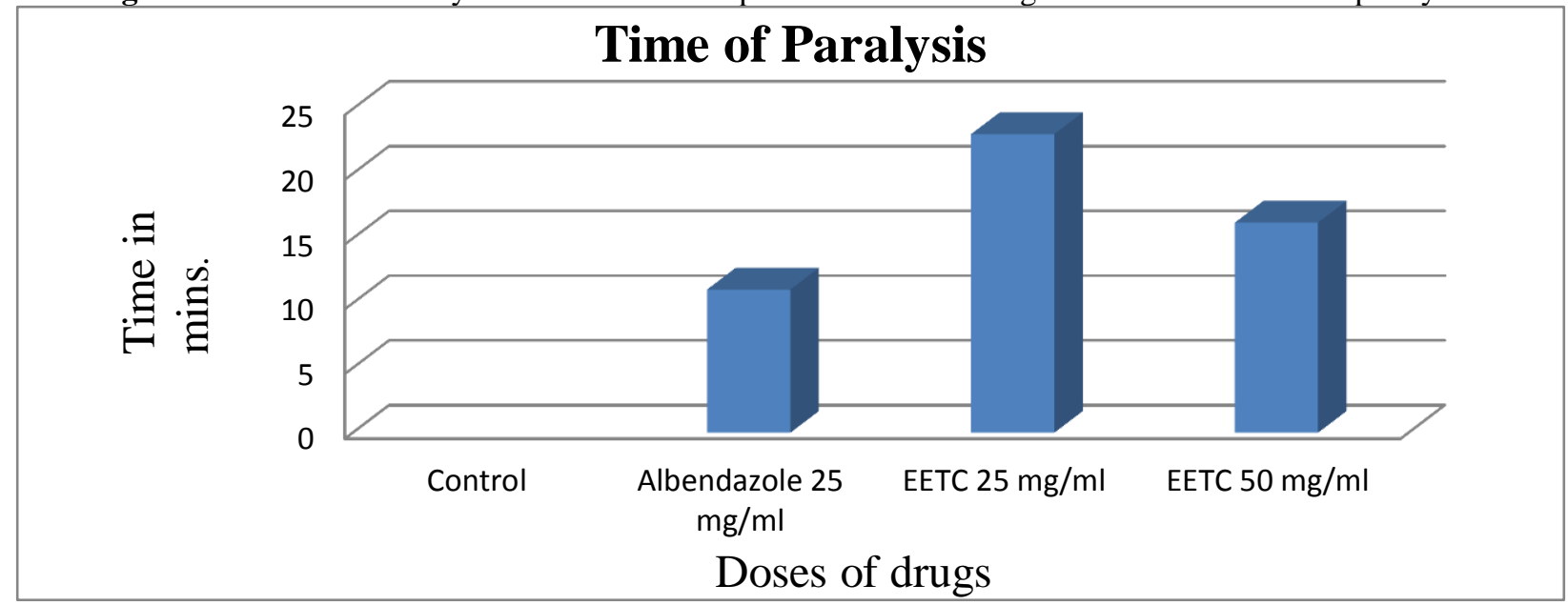

Fig 2:-Anihelmintic activity of EETC when compared to standard drug albendazole on time of death.

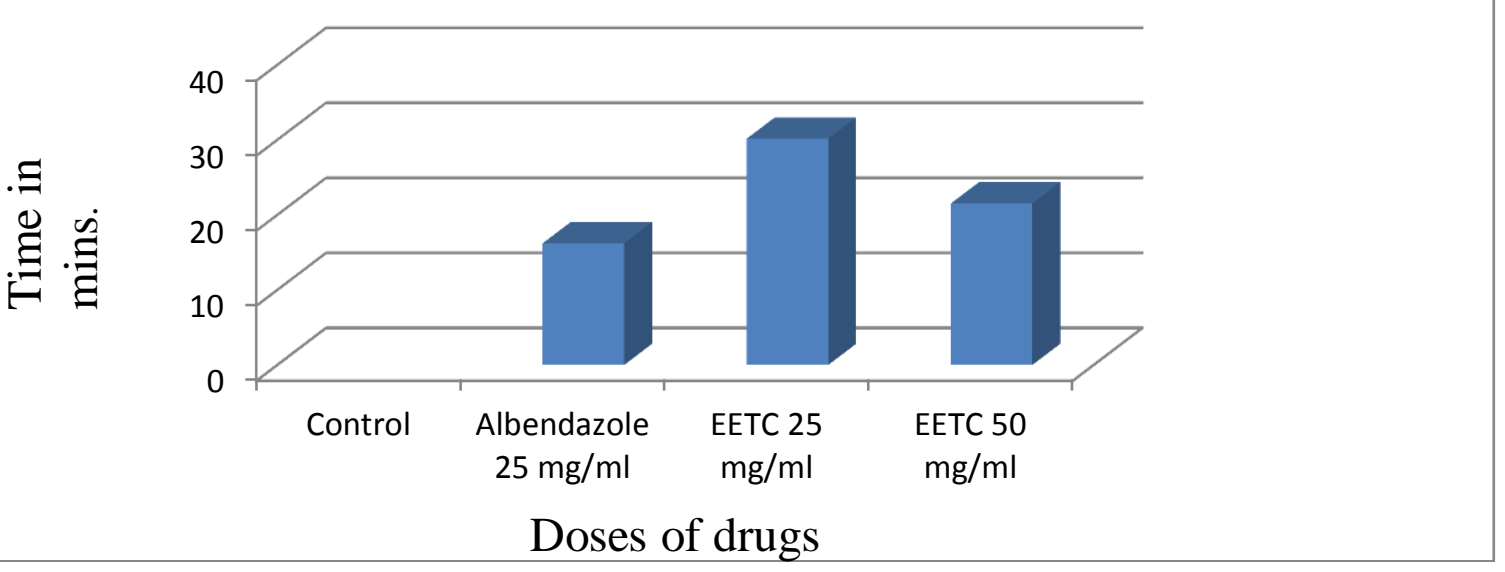




\section{Conclusion:-}

The present study enables us to conclude that ethanolic extract of leaves of Toona ciliata M. Roem (EETC) has significant anthelmintic activity $(\mathrm{p}<0.001)$ but less potent than the standard drug, albendazole. There was also definite increased anthelmintic activity of EETC at higher dose $(50 \mathrm{mg} / \mathrm{ml})$. Phytochemicals like tannins and polyphenols present in EETC could be responsible for the anthelmintic activity. ${ }^{22}$ However further studies with higher doses are required to evaluate the dose dependent anthelminthic activity and also to determine the active compound to find out the exact mechanism responsible for anthelmintic activity.

\section{References:-}

1. Cox FEG. History of human parasitology. Clin Microbiol Rev 2002;15(1):595-612.

2. Hotez PJ, Ottesen E, Fenwick A, Molyneux D. The neglected tropical diseases: the ancient afflictions of stigma and poverty and the prospects for their control and elimination. Adv Exp Med Biol 2006;582(1):23-33.

3. Das SS, Dey M, Ghosh AK.Determination of anthelmintic activity of the leaf and bark extract of Tamarindus indica Linn. Indian J Pharm Sci 2011;73(1):104-7.

4. Pullan RL, Smith JL, Jasrasaria R, Brooker SJ. Global numbers of infection and disease burden of soil transmitted helminth infections in 2010. Parasit Vectors 2014;7(37):1-19.

5. Abraham D, Kaliappan SP, Walson JL, Rao Ajjampur SS. Intervention strategies to reduce the burden of soiltransmitted helminths in India. Indian J Med Res 2018;147:533-44.

6. Chatterjee KD. Parasitology. $13^{\text {th }}$ ed. New Delhi: CBS Publishers \& Distributors Pvt. Ltd; 2015.

7. Weller PF, Nutman TB. Intestinal nematode infections. In: Kasper DL, Hauser SL, Jameson JL, Fuci AS, Longo DL, Loscalzo J, editors. Harrison's principles of internal medicine. $19^{\text {th }}$ ed. New York: McGraw Hill Education; 2015. p. 1413-17.

8. Tripathi KD. Essentials of medical pharmacology. $8^{\text {th }}$ ed. New Delhi: Jaypee Brother Medical Publishers(P) Ltd; 2019.

9. Keiser J, McCarthy J, Hotez P. Chemotherapy of helminth infections. In: Brunton LL, Hilal-dandan R, Knollmann BC, editors. Goodman and Gilman's the pharmacological basis of therapeutics. $13^{\text {th }}$ ed. New York: McGraw Hill Education; 2018. p. 1001-1010.

10. Yadav P, Singh R. A review on anthelmintic drugs and their future scope. Int J Pharm Pharm Sci 2011;3(3):1721.

11. Prakash R.Traditional uses of medicinal plants in Uttarakhand Himalayan region. Scholars Acad J Biosci 2014;2(5):345-53.

12. Chopra RN, Chopra IC, Handa KL, Kapur LD, editors. Indigenous drugs of India. $2^{\text {nd }}$ edition. Kolkata: Academic Publishers; 2006.

13. Sinha SC. Medicinal plants of Manipur. Imphal: Manipur Association for Science and Society; 1996.

14. Hossain H, Akbar PN, Rahman SE, Khan TA, Rahman MM, Jahan IA. In vivo anti- inflamatory and in-vitro anti-oxidant activities of Toona ciliata leaves native to Bangladesh. Global Journal of Medical Research: B Pharma, Drug Discovery, Toxicology and Medicine 2014;14(7):17-25 .

15. Divakar, Ratan P. Phytopharmacology of Toona ciliata: A review. Int Res J Pharm 2017;8(5):30-5.

16. Knevel AM, Digangi FE. Jenkins' quantitative pharmaceutical chemistry. $7^{\text {th }}$ ed. New York: McGraw Hill Book Co; 1977.

17. Vidyarthi RD. A textbook of zoology. $14^{\text {th }}$ ed. New Delhi: S Chand and Co; 1977.

18. Vigar Z. Atlas of medical parasitology. $2^{\text {nd }}$ ed. Singapore: PG Publishing House; 1984.

19. Mali RG, Hundiwale JC, Sonawane RS, Patil RN, Hatapakki BC. Evaluation of Capparis decidua for anthelmintic and antimicrobial activities. Ind J Nat Prod 2004;20(4):10-13.

20. Goswami S, Pandey A, Tripathi P, Singh A, Rai A. An in vitro evaluation of the anthelmintic activity of Hedychiumspichatum rhizomes and Zingiber zerumbet rhizomes on Pheritima posthuma model: A comparative study. Pharmagnosy Res 2011;3(2):140-2.

21. Kumar T, Pfuzia A, Banerjee P, Shougrakpam P, Paonam SD. Comparative study of in vitro anthelminthic activity of ethanolic extracts of Allium tuberosum Rottler ex spreng. and Trigonella foenum graecum L. on Indian earthworm. Int J Adv Res 2018;6(12):491-494.

22. Kaur S, Kumar B, PuriS, TiwariP, Divakar K. Comparative study of anthelmintic activity of aqueous and ethanolic extract of bark of Holoptelea integrifolia. Int J Drug Dev Res 2010;2(4):758-63. 